\title{
Electron Microscopy of Renal and Ocular Changes in Virus-Induced Diabetes Mellitus in Mice
}

\author{
M. Rodrigues ${ }^{1}$, C. Currier ${ }^{1}$ and J. Yoon ${ }^{2}$ \\ ${ }^{1}$ Clinical Branch, National Eye Institute, ${ }^{2}$ Laboratory of Oral Medicine, National Institute of Dental Research, National Institutes of Health, \\ Bethesda, Maryland, USA
}

\begin{abstract}
Summary. The eyes, kidneys and pancreas of mice (SJL/J) infected with encephalomyocarditis virus were examined by light and electron microscopy. Diabetic mice with the longest duration (6 months) of diabetes showed marked renal and ocular alterations. Fasting blood glucose levels were 17.8$21.9 \mathrm{mmol} / \mathrm{I}$ and glycosuria was present. Clinically, based on ophthalmoscopy and fluorescein angiography, retinal vessels were normal. Histologically, moderately decreased numbers of pericytes were noted following trypsin digestion. The basement membrane of inner retinal vessels showed significant thickening in diabetic mice. Corneal epithelial oedema was present and surface microvillus projections were decreased
\end{abstract}

compared with control mice. The kidneys of the same animals showed nodular and diffuse glomerulosclerosis and mesangial thickening. Electron microscopy showed excessive accumulation of basement membrane-like material in the mesangium and the peripheral glomerular region. Histologically, moderate to advanced kidney disease was associated with relatively early retinopathy.

Key words: SJL/J mice, virus-induced diabetes, basement membrane, retinal vessels, cornea, kidney, electron microscopy.
In an effort to clarify the pathogenesis of late diabetic complications, a variety of animal models have been investigated $[1,2]$. Besides primates and dogs, these include rodents such as genetically hyperglycaemic $\mathrm{db}+/$ $\mathrm{db}+$ mice and rats made hyperglycaemic with alloxan and streptozotocin $[1,2]$. These animal models can develop structural changes resembling human diabetes if the duration of poor metabolic control is prolonged $[1,2]$.

There is evidence that viruses are one cause of insulin-dependent diabetes $[1,3,4]$ and the best evidence of this comes from experiments in mice [5]. The most studied virus is the $M$ variant of encephalomyocarditis (EMC) virus. However, long-term complications have been difficult to demonstrate with the $M$ variant, for in most mice, the diabetes is transient and very mild. Recently by plaque purification, it has been shown that the $M$ variant of EMC virus actually has two stable variants: one diabetogenic ( $\mathrm{D}$ variant) and the other nondiabetogenic (B variant) [6]. When the $\mathrm{D}$ variant of EMC virus was inoculated into mice, severe hyperglycaemia developed in $85 \%-90 \%$ of the animals $[6,7]$. The present study was initiated to evaluate the morphologi- cal changes in long-term diabetic mice and to determine whether such changes are comparable to those seen in human diabetes.

\section{Materials and Methods}

\section{Animals}

$\mathrm{SJL} / \mathrm{J}$ male mice were obtained from the Jackson Laboratory, Bar Harbor, Maine, USA. Mice were maintained on Purina NIH mouse ration containing $5.0 \%$ fat and $23.5 \%$ protein. Except where noted, 5-6 week-old-mice were used for inoculation in all experiments.

\section{Virus}

The preparation of a source of D variant of EMC virus has been described elsewhere [6]. Except where noted, mice were inoculated intraperitoneally with $5 \times 10^{5}$ plaque-forming units of virus per mouse.

\section{Glucose Assay}

Blood was obtained from the retro-orbital venous plexus of mice. Glucose levels were measured enzymatically by the glucose oxidase method with p-dianisidine dihydrochloride as the reactive dye [8]. 
Blood for glucose tolerance tests was obtained $60 \mathrm{~min}$ after intraperitoneal injection of glucose $(2 \mathrm{mg} / \mathrm{g}$ weight of the animal). Non-fasting glucose levels were measured at $0,7,30,60,90,120,150$ and 180 days after infection. Any mouse with non-fasting glucose level $>3 \mathrm{SD}$ above the mean non-fasting glucose level of an age-matched uninfected control was considered as diabetic.

\section{Histopathology}

Groups of diabetic congenic, and age-matched control animals were killed at specific intervals after infection, at $2 \frac{1}{2}, 4,6$ and 7 months. Portions of kidneys, eyes, pancreas, skeletal muscles, heart and peripheral nerves were fixed in formalin and processed for routine microscopy. Paraffin embedded sections were stained with hematoxylin and eosin, periodic acid Schiff and Masson trichrome. Portions of retina were prepared for trypsin digest as previously described [9]. For transmission electron microscopy other portions of kidneys and eyes were fixed in $2.5 \%$ buffered glutaraldehyde, postfixed in osmium tetroxide, dehydrated in ascending concentrations of alcohols and embedded in epon. Thin sections were stained with uranyl acetate and lead citrate and examined with a Philips 400 electron microscope (Eindhöven, The Netherlands). For scanning electron microscopy, specimens were fixed in 3\% buffered glutaraldehyde, postfixed in osmium tetroxide, dehydrated in graded acetone, critical point dried, coated with gold and examined with the JEOL SM35 scanning electron microscope (Tokyo, Japan).

\section{Statistical Methods}

The statistical significance of the difference between the means of the sample groups was tested by the Student's t-test with a Welch adjustment for unequal variances where necessary [10]. The significance level of $p>0.001$ was used as a criterion of differences.

\section{Results}

\section{Virus-Induced Metabolic Alteration}

When mice were inoculated with the D variant of EMC virus, the mean blood glucose level reached $23.9 \mathrm{mmol} / 17$ days after infection and $85 \%$ of the animals were hyperglycaemic. The severity of the hyperglycaemia and the percentage of diabetic animals, however, continuously decreased. At 30 days after inoculation, the mean non-fasting glucose level was $22.2 \mathrm{mmol} / 1$ and $78 \%$ of the animals were hyperglycaemic. After 6 months, the mean blood glucose was $14.3 \mathrm{mmol} / 1$ and only $16 \%$ of the animals still had elevated glucose levels. In contrast, age-matched uninfected mice showed no elevation of blood glucose.

Table 1. Effect of blood glucose level on mortality in diabetic mice

\begin{tabular}{|c|c|c|c|c|c|}
\hline \multirow[t]{2}{*}{$\begin{array}{l}\text { Days after } \\
\text { infection }\end{array}$} & \multirow{2}{*}{$\begin{array}{l}\text { No. of } \\
\text { diabetic } \\
\text { animals }\end{array}$} & \multicolumn{2}{|c|}{$\begin{array}{l}\text { Glucose level } \\
>\text { the median }\end{array}$} & \multicolumn{2}{|c|}{$\begin{array}{l}\text { Glucose level } \\
<\text { the median }\end{array}$} \\
\hline & & $\begin{array}{l}\text { No. of } \\
\text { mice }\end{array}$ & $\begin{array}{l}\text { No. of } \\
\text { deaths }(\%)\end{array}$ & $\begin{array}{l}\text { No. of } \\
\text { mice }\end{array}$ & $\begin{array}{l}\text { No. of } \\
\text { deaths }(\%)\end{array}$ \\
\hline 30 & 84 & 42 & $8(19)$ & 42 & 1 (2) \\
\hline 60 & 78 & 39 & $10(26)$ & 39 & $6(15)$ \\
\hline 90 & 60 & 30 & $7(23)$ & 30 & $3(10)$ \\
\hline 120 & 42 & 21 & $13(62)$ & 21 & $3(14)$ \\
\hline
\end{tabular}

When the non-fasting glucose levels of 12 individual diabetic animals were examined over 150 days after infection, three general patterns were observed. The most common pattern, found in half of the diabetic animals, was a transient severe hyperglycaemia lasting from 1 to 3 months. The second, occurring in $<10 \%$, was persistent severe hyperglycaemia of $>22.2 \mathrm{mmol} / 1$ for at least 150 days. The third pattern, found in about $40 \%$ of animals, was characterized by a mild persistant hyperglycaemia. Seven of these 12 animals died between 5 and 6 months after infection, and the remaining five, with elevated blood glucose levels, survived for 6 months.

To study the relationship between virus-induced hyperglycaemia and immunoreactive insulin (IRI), mice were infected with the $\mathrm{D}$ variant of EMC virus and at different times thereafter, the concentration of plasma IRI was determined and plotted against the non-fasting glucose concentration. Up to 150 days after infection, the animals could be segregated into two groups: (1) normal plasma IRI and normal glucose levels and (2) depressed plasma IRI and elevated glucose levels. However, at 180 days after infection, plasma IRI levels were elevated and glucose levels decreased, probably due to the significantly increased mortality of severely diabetic mice. The remaining animals had relatively mild diabetes, probably secondary to regeneration of B cells.

\section{Mortality Rate}

The mortality of diabetic mice was 10-20 times higher than that of non-diabetic animals, which were either infected or uninfected during the observation period. There was no noticeable difference in mortality between infected diabetic and uninfected mice. The mortality of diabetic mice increased continuously from $7 \%$ at 30 days to $58 \%$ at 180 days after infection. The cumulative mortality of infected animals was four- to 20 -fold higher than that of age-matched uninfected animals during the observation period. The cumulative mortality of infected mice on day 60 after infection was $21 \%$. In contrast, only $1 \%$ of uninfected animals died during this period. The cumulative mortality of the infected mice was $65 \%$ at 180 days after infection, while only $17 \%$ mortality was observed in the uninfected group.

To see a correlation between mortality and non-fasting glucose levels, diabetic mice were divided into groups having higher and lower blood glucose levels than the median of non-fasting glucose levels of diabetic mice. The higher blood glucose group showed significantly higher mortality than the lower blood glucose group (Table 1).

\section{Histopathological Changes}

In animals with approximately $2 \frac{1}{2}$ months duration of diabetes, light microscopic examination of the kidneys showed slight thickening of Bowman's capsule and 


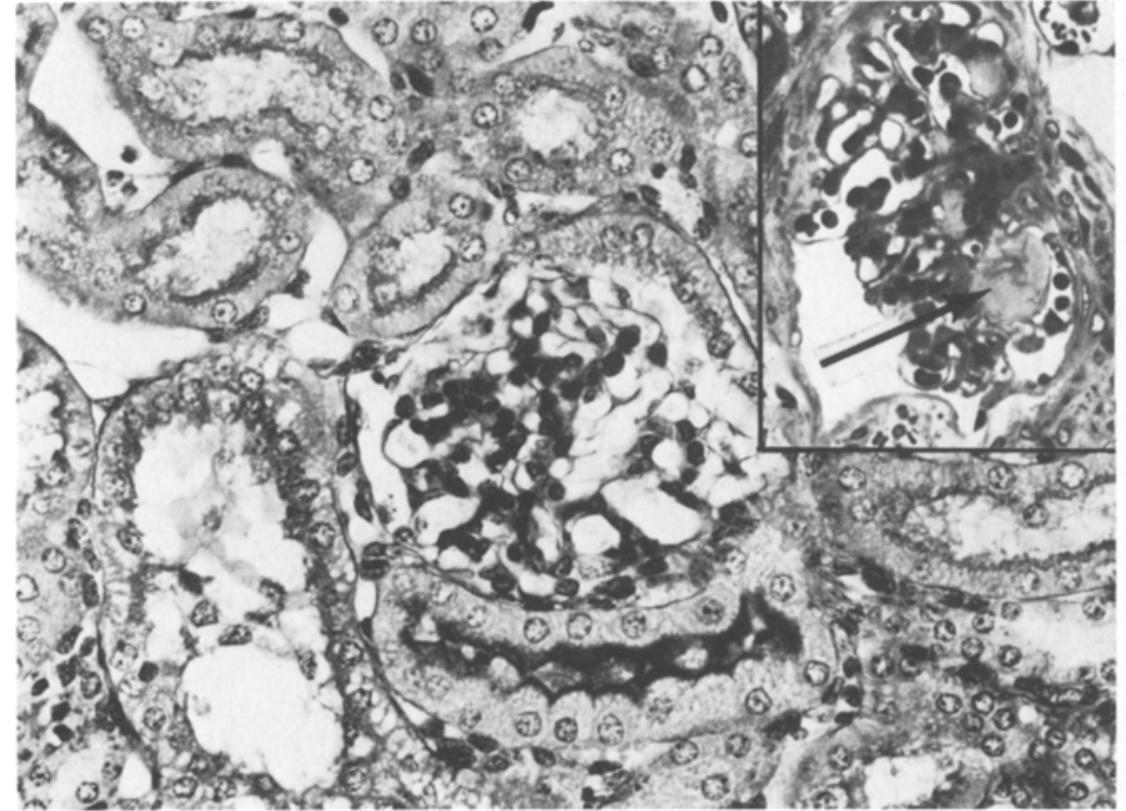

Fig. 1. Normal mouse kidney (periodic acid Schiff $\times 330$ ). Inset shows nodular glomerulosclerosis (arrow) in a 6-month diabetic mouse (Toluidine blue $\times 330$, original magnification) mesangial matrix in contrast to age-matched control mice. This finding increased with progressive duration of diabetes until at 6 months the kidneys showed markedly thickened Bowman's capsule and nodular and diffuse glomerulosclerosis in contrast to those of agematched controls (Fig. 1). The afferent and efferent arterioles showed evidence of hyaline sclerosis.

Transmission electron microscopy showed progressive thickening of peripheral glomerular basement membrane and mesangium as well as fusion of foot processes. In animals with 6 months duration of diabetes, there was moderate thickening of peripheral glomerular basement membrane (Fig. 2) and marked thickening of mesangium. The peripheral glomerular basement membrane measured $382 \pm 6 \mathrm{~nm}$ in mice that were diabetic for 6 months, compared with a thickness of $91 \pm 3 \mathrm{~nm}$ in uninfected controls, as measured by Siperstein's method [11]. Approximately 20 glomeruli from each of 12 control and 12 diabetic mice were examined and 10-20 measurements were made per sample. Control animals showed normal glomerular structure with distinct delineation of the glomerular epithelial cells, the lamina lucida externa and interna, lamina densa and fenestrated endothelial cells (Fig. 2).

Scanning electron microscopy of the control glomeruli disclosed normal contour pedicels and foot processes (Fig.3). In 6 month diabetic mice, the normal configuration was markedly altered; some glomeruli were markedly atrophic and Bowman's capsule showed marked thickening and scarring (Fig. 3).

Frequent clinical examination of the eyes showed no abnormalities. Fluorescein angiograms of control and diabetic mice were normal. Light microscopy of the 6 month diabetic mice revealed irregularity and oedema of the corneal epithelium involving all layers particular- ly the basal layer, confirmed by scanning electron microscopy (Fig.4). Transmission electron microscopy disclosed that the junctional complexes were deficient in some areas (Fig. 5). Control mice showed normal stratification of the corneal epithelium and preservation of junctional complexes (Fig. 5).

The basement membrane of retinal capillaries each measured in ten different areas showed slight to moderate thickening in diabetic animals compared with agematched control mice (Fig. 6). In eight diabetic animals the retinal vascular basement membrane thickness was $91 \pm 10.2$ versus $69 \pm 5.5 \mathrm{~nm}$ in control mice (mean \pm $\mathrm{SD}, p>0.001$ ) [10]. The retinal vessels in diabetic mice also showed a $40 \%$ decrease in pericytes compared with controls. There was no evidence of microaneurysms or other capillary or arteriolar changes. As with kidney changes, the ocular pathological changes were present to a lesser degree in diabetic animals with a shorter duration of disease. The lens, iris and ciliary epithelium, choroid and optic nerve were unremarkable.

The pancreas at all stages showed marked atrophy of the B cells of the islets of Langerhans. The acinar cells appeared intact. Heart, skeletal muscles and peripheral nerves appeared unremarkable histologically.

\section{Discussion}

Spontaneous and induced diabetes in experimental animals are useful models for the study of various aspects of human diabetes, although no animal syndrome conforms exactly to the human disease [2]. Renal involvement in animal models is often limited to mesangial thickening [12], which contrasts with human diabetes, where the increase in mesangial matrix is considered 

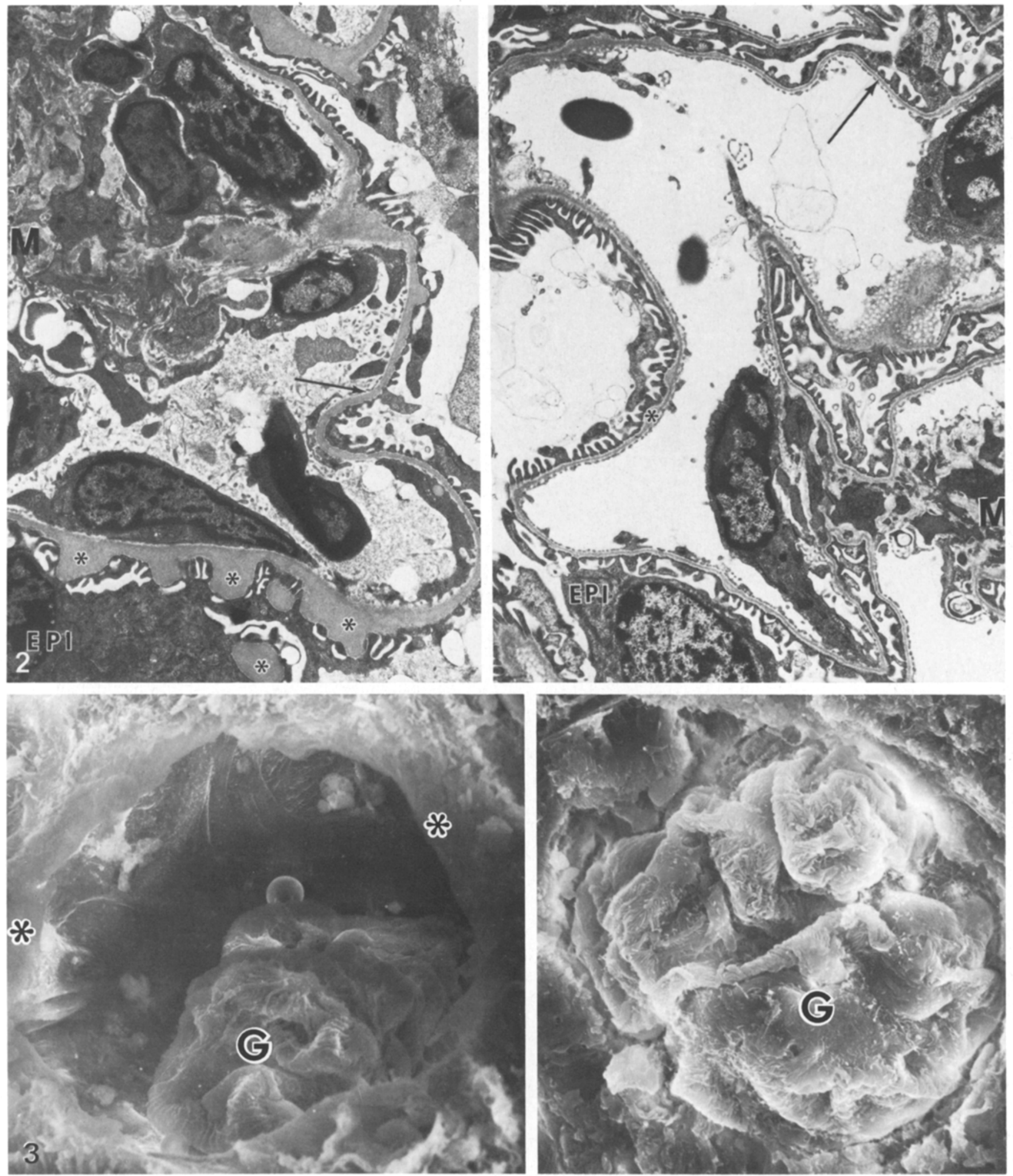

Fig. 2. Transmission electron micrograph of a 6-month diabetic mouse kidney. Left: There is marked thickening of the peripheral glomerular basement membrane (arrow) with prominent excrescences $(*)$. Widening of the mesangial matrix (M) is also present. A glomerular epithelial cell is indicated (EPI) ( $\times 9900$, original magnification). Right: Normal mouse kidney showing fenestrations along the endothelial surface (arrow); glomerular basement membrane is indicated $\left(^{*}\right)$; mesangium $(\mathrm{M})$ and glomerular epithelial cell (EPI) $(\times 9900$, original magnification)

Fig. 3. Scanning electron micrograph showing: Left: Diabetic mouse ( 6 month duration) with thickened Bowman's capsule (*) and atrophic glomerulus $(G)(\times 1483$, original magnification). Right: Normal glomerulus $(G)$ ( $\times 2374$, original magnification) 

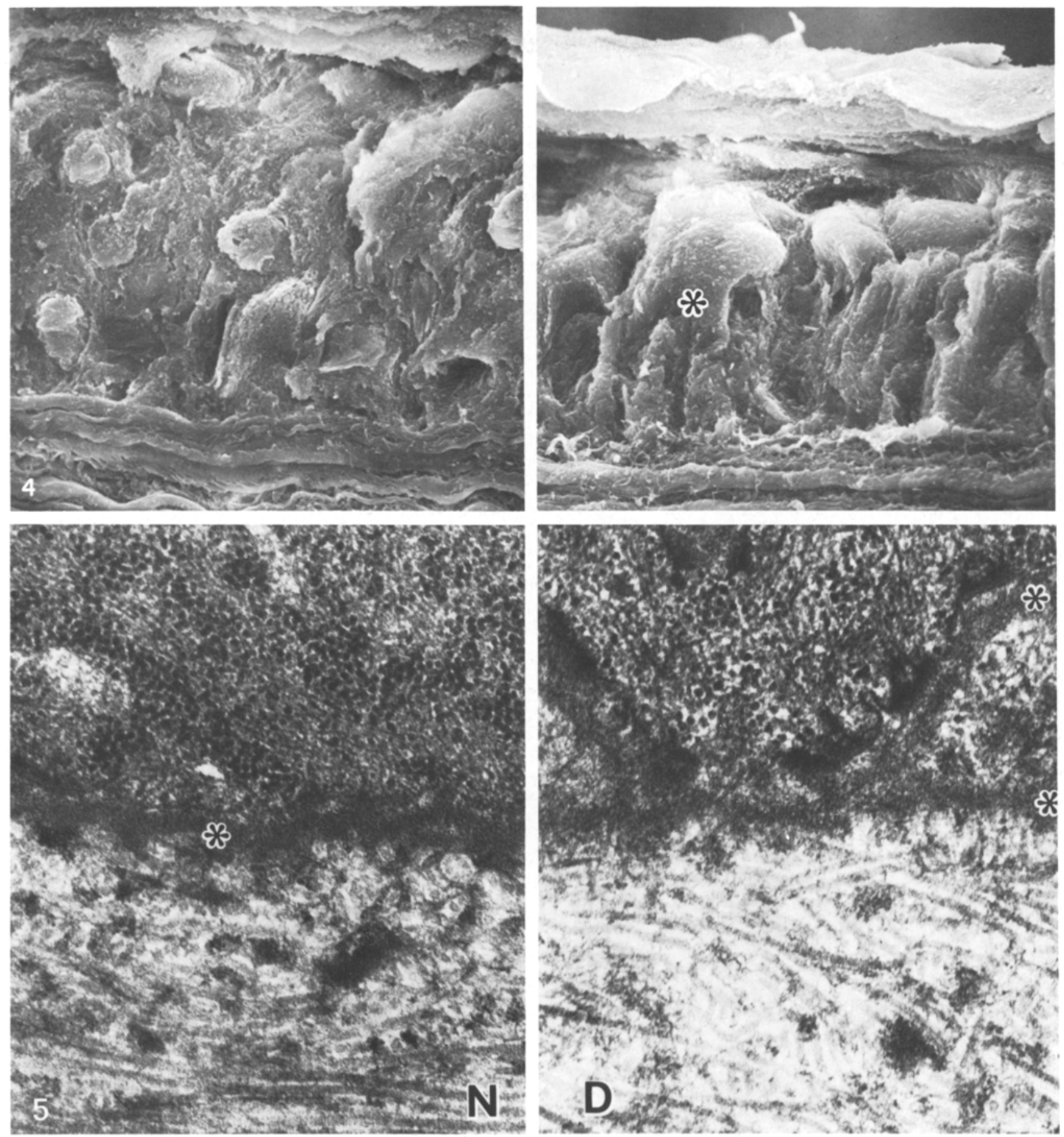

Fig. 4. Left: Corneal epithelium from a normal mouse $(\times 1000$, original magnification). Right: Scanning electron micrograph of diabetic (6-month mouse) corneal epithelium showing oedema and irregularity of the basal cells $(*)(\times 1000$, original magnification)

Fig.5. Left: Corneal epithelial basement membrane is indicated $\left(^{*}\right)$ in normal mouse $(\mathrm{N})(\times 75,000$, original magnification). Right: Diabetic 6 -month mouse (D). Irregular basement membrane $(*)$ with disruption of junctional complexes $(\times 75,000$, original magnification)

less characteristic of the disease than the subsequent glomerular basement membrane changes.

In a previous report, using the $\mathrm{M}$ variant of EMC virus, which produces mild and transient diabetes, $\mathrm{Ka}$ nich et al. [13] observed some mesangial thickening in diabetic mice by transmission electron microscopy; this was not associated with the thickness of the peripheral glomerular basement membrane and Bowman's capsule, or with nodular and diffuse glomerulosclerosis, and afferent and efferent arteriosclerosis, all of which are typical of renal complications seen in human diabetes. 


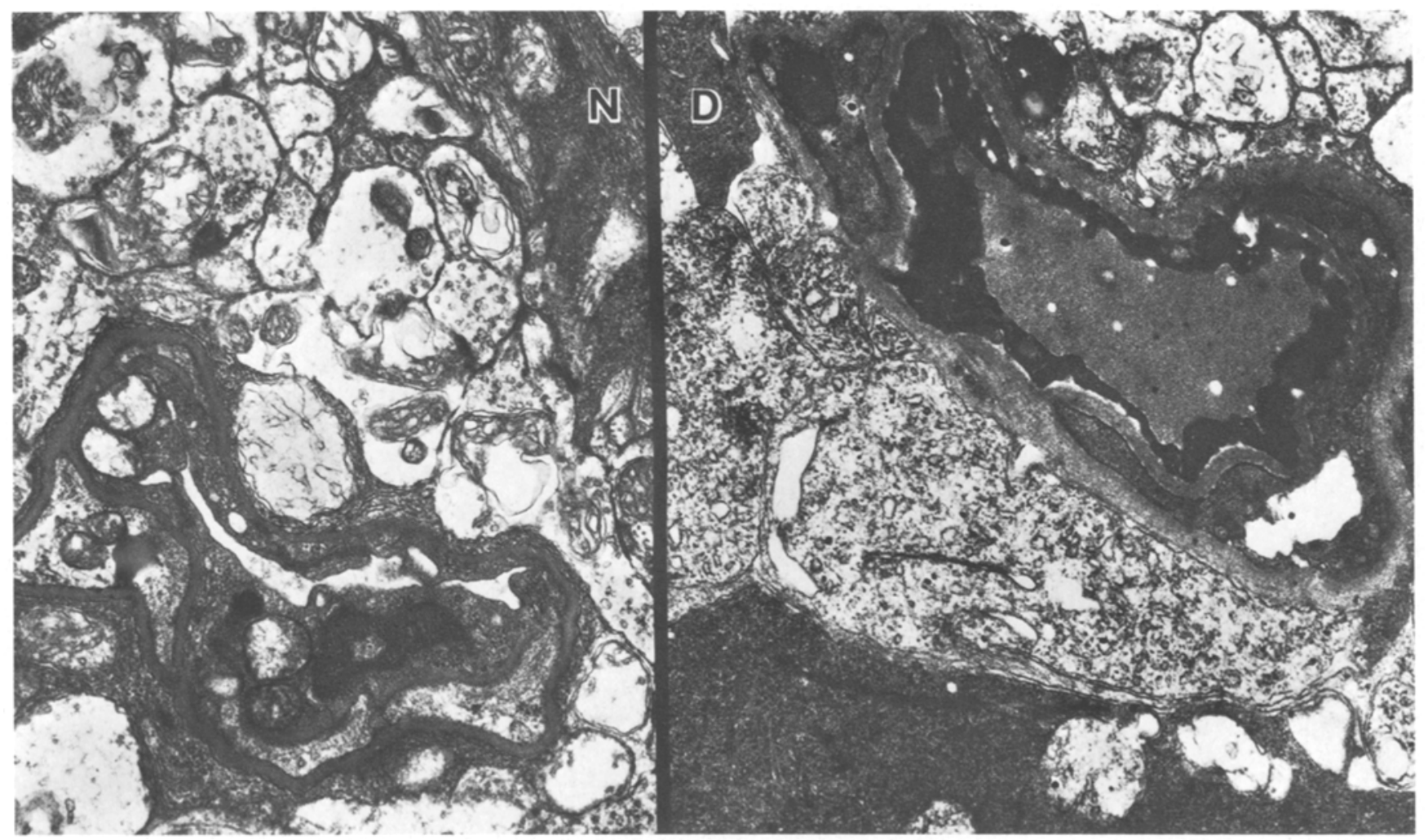

Fig. 6. Transmission electron micrograph of inner retinal vessels. The endothelial basement membrane is thicker in the diabetic mouse (D) compared to a normal $(N)$ mouse at the same magnification $(\times 27,000$, original magnification)

Our murine model is of particular interest because it develops kidney changes similar to those found in man. Mauer et al. [12] have described the essential features of human diabetic nephropathy in terms of structural changes. These authors noted invariable glomerular basement membrane thickening, especially of the lamina densa, and mesangial widening (diffuse glomerulosclerosis) that together were diagnostic of diabetic kidney disease [12]; Kimmelstiel Wilson nodules (nodular glomerulosclerosis) and glomerular arteriolar hyalinization were frequently present and hyaline lesions and parietal Bowman's capsule surface lesions occasionally occurred. Our animal model developed both mesangial widening with increased matrix material and glomerular basement membrane thickening characteristic of human nephropathy. These renal changes were related to the duration of diabetes; milder involvement at $4 \frac{1}{2}$ months and greater changes by 6 months.

Basement membrane alterations involving retinal capillaries and corneal epithelium were present also in our diabetic mice, although the changes were mild compared with kidney involvement in the same animals. Statistical analysis of the basement membrane thickness of retinal vessels in our animals showed a significant increase in diabetic animals. Excessive accumulation of basal lamina with layering in the capillaries in human diabetes may be related to episodes of cell death and cell replacement [14]. We did not observe microaneu- rysms of fusiform dilatations of retinal vessels. The lesser degree of ocular involvement compared to the marked renal changes is consistent with differences between small and large animal models and is typical of the difficulties encountered in finding suitable animal models for ocular diabetes [15].

Corneal changes in human diabetes include slowly healing abrasions with a propensity for corneal erosions. Thickening of the corneal epithelium basement membrane in maturity-onset diabetic patients was reported recently [16]. Our animals showed basal layer irregularity and altered junctional complexes. Defective corneal wound healing in diabetic and galactosemic rats [17] and diabetic patients has been reported by some investigators [18] while others have observed normal healing [19]. The delay in corneal re-epithelialization in the diabetic rat could be improved by aldose reductase inhibitors [20]. The absence of cataracts in our mice could be due to the low levels of aldose reductase in mouse lens compared with the rat lens. Varma and Kinoshita [21] found the activity in various mouse lenses to be $0.6-1.3$ units $/ \mathrm{mg}$ wet weight of tissue, about one-twentieth to one-tenth of that present in the rat. Aldose reductase appears to initiate cataractous changes in diabetic and galactosemic animals [21].

Certain pathological changes present in man and some animal models have not been found in our virusinduced mice; these include cardiac myopathy and 
atherosclerosis. The normal cardiac histology in our mice indicates that mortality is due to renal dysfunction rather than to myocardial damage. Reports of skeletal muscle involvement have included capillary basement membrane thickening which may be secondary to nerve damage. In the present study, skeletal muscle biopsies were histologically normal, as were distal nerves which have appeared abnormal in certain models.

Our murine model demonstrated several characteristics of diabetes: (1) the pathology is limited to the diabetic animals without involving age-matched congenic controls; (2) severity of diabetic changes is proportional to the duration of diabetes, though this may be modified by genetic factors, since SJL mice show the most severe renal changes; (3) the basement membrane alterations in this model are consistent with such changes in diabetic animal as well as in human diabetes.

Acknowledgements. We thank Drs. G. Martin and T.Antonovych for their suggestions. J. Hackett, P.Donohoo, R. Gaskins, and K. Patterson provided technical assistance.

\section{References}

1. Craighead JE (1981) Viral diabetes mellitus in man and experimental animals. Am J Med 70: 127-134

2. Mordes JP, Rossini AA (1981) Animal models of diabetes. Am J Med 70:353-360

3. Gamble DR (1982) The epidemiology of insulin-dependent diabetes with particular reference to the relationship of virus infection to its etiology. Epidemiol Rev 2: 49-56

4. Notkins AL, Yoon J, Onodera T, Toniolo A, Jensen AB (1981) Virus induced diabetes mellitus. In: Pollard $M($ ed) Perspective in virology. Alan R Liss, New York 11: 141-162

5. Yoon JR (1982) Viruses and the pathogenesis of insulin-dependent diabetes mellitus. In: Melish JS, Hanna J, Baba S (eds) Genetic environmental interaction in diabetes mellitus. International Congress Series 549. Excerpta Medica, Amsterdam, pp 227-234

6. Yoon JW, McClintock AR, Onodera T, Notkins AL (1980) Virus induced diabetes mellitus. Inhibition by a non-diabetogenic variant of encephalomyocarditis virus. J Exp Med 152: 878-892
7. Yoon J, Rodrigues MM, Currier C, Notkins AL (1982) Long-term complications of virus-induced diabetes mellitus in mice. Nature 296: $566-569$

8. Raabo E, Terkildsen TC (1960) On the enzymatic determination of blood glucose. Scan J Clin Lab Invest 12: 402-407

9. Cogan DG, Toussaint D, Kuwabara T (1961) Retinal vascular patterns. IV. Diabetic retinopathy. Arch Ophthalmol 66: 366-378

10. Brownlee KA (1965) Statistical theory and methodology in science and engineering. Wiley, New York

11. Siperstein $M$ (1972) Capillary basement membranes and diabetic microangiopathy. Adv Intern Med 18: 325-344

12. Mauer SM, Steffes NM, Brown DM (1981) The kidney in diabetes. Am J Med 70: 603-612

13. Kanich RE, Craighead ME, Kessler JB (1973) Lesions of renal glomeruli in mice with virus-induced diabetes mellitus-like disease. Diabetologia 9: 203-209

14. Vracko R (1974) Evidence of accelerated rate of cell death and cell regeneration. Diabetes 23:94-104

15. Engerman R, Finkelstein D, Aguirre G, Diddie KR, Fox RR, Frank RN, Varma SC (1982) Ocular complications. Diabetes 31: $82-88$

16. Taylor HR, Kimsey RA (1981) Corneal epithelial basement membrane change in diabetes. Invest Ophthalmol Vis Sci 20: 548-553

17. Fukushi S, Merola LO, Tanaka M, Datiles M, Kinoshita JR (1981) Re-epithelialization of denuded corneas in diabetic rats. Exp Eye Res 31:611-621

18. Foulks GN, Thoft RA, Perry HD (1979) Factors related to corneal epithelial complications after closed vitrectomy in diabetes. Arch Ophthalmol 97: 1076-1078

19. Snip RC, Thoft RA, Toletino FI (1980) Similar epithelial healing rates of corneas of diabetic and nondiabetic patients. Am J Ophthalmol 90: 463-468

20. Kinoshita J, Fukushi S, Kador P, Merola LO (1979) Aldose reductase in diabetic complications of the eye. Metabolism 28: 462-469

21. Varma SD, Kinoshita JR (1974) The absence of cataracts in mice with congenital hyperglycemia. Exp Eye Res 19: 577-578

Received: 23 March 1982

and in revised form: 20 December 1982

Dr. M. M. Rodrigues

Building 10, Room 10N315

National Eye Institute, National Institutes of Health

Bethesda, Maryland 20205, USA 